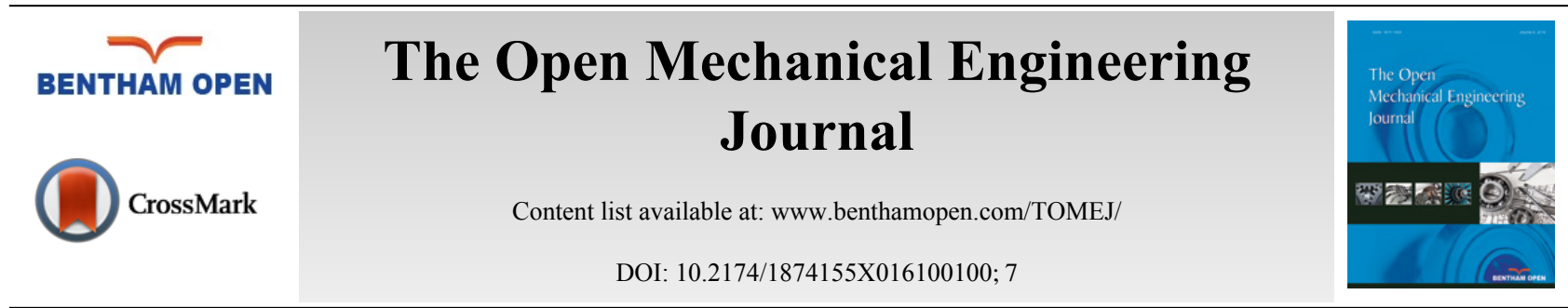

\title{
Retraction Notice: Simulation Modeling and Application of Travel Mode Choice Based on Bayesian Network
}

\author{
Ruijing Chen ${ }^{*}$
}

Fujian Chuanzheng Communications College, Fuzhou, China

\section{RETRACTION}

The Publisher and Editor have retracted this article [1] in accordance with good ethical practices. After thorough investigations we believe that the peer review process was compromised. The article was published online on 21-03-2014.

\section{REFERENCE}

[1] R. Chen, "Simulation Modeling and Application of Travel Mode Choice Based on Bayesian Network", Open Mech. Eng. J., vol. 8, pp. 19-25, 2014.

(C) Ruijing Chen; Licensee Bentham Open.

This is an open access article licensed under the terms of the Creative Commons Attribution-Non-Commercial 4.0 International Public License (CC BY-NC 4.0) (https://creativecommons.org/licenses/by-nc/4.0/legalcode), which permits unrestricted, non-commercial use, distribution and reproduction in any medium, provided the work is properly cited.

\footnotetext{
* Address correspondence to this author at the Fujian Chuanzheng Communications College, Fuzhou, China; Tel: 0086-591-83511366; Fax:
} 0086-591-83441953; E-mail: ruijing_chen@163.com 